\title{
To Assess the Effectiveness of Planned Teaching on Knowledge of Ganja Addiction Hazards, and Its Prevention among Male Adolescents
}

\author{
Suvarna Banduji Ghugare ${ }^{1}$, Archana Tej Mourya² \\ ${ }^{1}$ Department of Child Health Nursing, Smt. Radhikabai Meghe Memorial College of Nursing, Datta Meghe Institute of \\ Medical Sciences, Wardha, Maharashtra, India. ${ }^{2}$ Department of Child Health Nursing, Smt. Radhikabai Meghe \\ memorial College of Nursing, Datta Meghe Institute of Medical Sciences, Wardha, Maharashtra, India.
}

\section{ABSTRACT}

\section{BACKGROUND}

Marijuana may be smoked, braided as a tea, or consumed in foods such as brownies and chocolate bars. Many people treat chronic pain, muscle spasm, anorexia, pneumonia and sleep disorders with medical marijuana. Medical marijuana means whole marijuana or its ingredients, on which a few licensed drugs are based, such as cannabidiol (CBD). The government does not standardize medical marijuana and does not recognize its strength and ingredients. Not legal in any state. We wanted to assess the existing knowledge regarding hazards of ganja and prevention among male adolescents in selected senior secondary school to evaluate effectiveness of planned teaching regarding hazards of ganja and prevention among male adolescent in selected senior secondary school.

\section{METHODS}

This is a pre-test and post-test study based on evaluative approach. The sample was 60 senior secondary school male adolescents from a selected senior secondary school in Sawangi, Wardha. Self-administered questionnaire having $30 \mathrm{MCQs}$ was given to the study participants. The correct answer got score 1 and wrong score got 0 score.

\section{RESULTS}

The mean score of posttest knowledge 16.80 was apparently higher than the mean score of pre-test knowledge 7.45. There was significant difference between the mean pre-test and post-test knowledge score $(t=22.024, p=0.095)$ at $\mathrm{p}<0.05$ level and no significant association was found between selected demographic variables.

\section{CONCLUSIONS}

Planned teaching was highly effective in enhancing the knowledge regarding hazards of ganja, and its prevention among male adolescents in the selected senior secondary school.

\section{KEY WORDS}

Effectiveness, Knowledge, Male Adolescent, Prevention, Hazards
Corresponding Author:

Dr. Suvarna Banduji Ghugare,

Shankar Nagar, Near Reliance Tower at

Sindhi Railway Taluka Seloo, Dist. Wardha,

Maharashtra, India.

E-mail: suwarna.ghugare1990@gmail.com

DOI: $10.14260 /$ jemds/2020/551

How to Cite This Article:

Ghugare SB, Mourya AT. To assess the effectiveness of planned teaching on knowledge of ganja addiction hazards and its prevention among male adolscents. J Evolution Med Dent Sci 2020;9(35):25362539, DOI: $10.14260 /$ jemds/2020/551

Submission 27-05-2020,

Peer Review 21-07-2020

Acceptance 27-07-2020,

Published 31-08-2020.

Copyright (C) 2020 JEMDS. This is an open access article distributed under Creative Commons Attribution License [Attribution 4.0 International (CC BY 4.0)] 


\section{BACKGROUND}

Natural cannabinoids serve as neurotransmitters, transmitting chemical signals in the nervous system and nerve cells (neurons). These neurotransmitters affect memory, mind, attention, motion, balance, visual, perception of time as well as pleasure areas in the brain. The receptors which respond to these cannabinoids also respond to THC that can alter and disturb the normal function of the brain affect brain regions which control the development and attention of memory. It also interferes with other brain parts, affecting balance, posture, coordination and time of reaction. This could lead to insecurity in the driving of cars, heavy machinery, sports or other potentially harmful physical activities for anyone using marijuana. ${ }^{1}$ THC (tetrahydrocannabinol) also activates the release of dopamine, a fun-related neurotransmitter, through unique cannabinoid receptors.

People use marijuana to get a feeling of fun, giddiness and relaxation. Marijuana also induces improvements in sensory perception, colors, vivid music and deeper emotions. Some people have anxiety feelings. ${ }^{2}$ People can smoke marijuana, inhale it through vapor, brew it as a tea, apply it as a balm, or eat it in product, such as brownies or chocolate bars. Some people use medical marijuana to treat chronic pain, muscle spasticity, anorexia, nausea, and sleep disturbances. Medical marijuana refers to either whole marijuana or its ingredients, such as cannabidiol, which form the base of a limited number of approved medications. Medical marijuana is not subject to government standardization, making its ingredients and potency unknown. It is not legal in all stayes. ${ }^{3}$ According to UN report, one million heroin addicts are registered in India and unofficially there is as much as five million. Cannabis, Heroin and Indian Produced pharmaceutical Drugs are the most frequently abused drugs in India. The International Narcotic Contro Board reported that in India person addicted to opiates are shifting their drug of choice from opium to heroin Srivastava, A Pal, HR Dwivedi et al 2003.

Various studies in India shows that $80 \%$ of Adults starts using psychoactive substance before 18 years of age and if they continue with its addiction may be developed within three years with increased risk of physical and mental illness Singhi S l, Broca JS, Mathur GM 2007.

\section{Objectives}

1. To assess the existing knowledge regarding hazards of ganja and prevention among male adolescent in selected senior secondary school.

2. To evaluate the effectiveness of planned teaching regarding hazards of ganja and prevention among male adolescents in selected senior secondary school.

3. To evaluate the association between post-test knowledge scores regarding hazards of ganja use and prevention of the same among male adolescents.

\section{METHODS}

The research took place from August 2018 to July 2019, in Sawangi High School, having got approval from the Institutional Ethics Committee and written informed consent from the students in their vernacular language. ${ }^{4}$ this is a quasiexperimental study with pre - post design. The sample was taken for conveniences and the sample size was 60.60 male adolescents (14 to 16 years of age) from Sawangi High School were included in the study. Male adolescents of selected senior secondary school who are not available at the time of data collection and who are not interested to participate in the study were excluded from the study.

Self-administered questionnaire having 20 MCQs. the correct answer got score 1 and wrong score got 0 score. To associate knowledge score with demographic variable.

\section{Statistical Analysis}

Data was analysed using the SPSS version 22.0, GraphPad Prism 6.0. $\mathrm{p}<0.05$ was considered the level of statistical significance using the chi square test, student paired test, oneway ANOVA.

\section{RESULTS}

\begin{tabular}{|c|c|c|}
\hline Demographic Variable & Frequency & Percentage (\%) \\
\hline $13-14$ & 27 & $45 \%$ \\
\hline $15-16$ & 22 & $36.67 \%$ \\
\hline $17-18$ & 11 & $18.33 \%$ \\
\hline \multicolumn{3}{|c|}{ Residential Area } \\
\hline Urban & 45 & $75 \%$ \\
\hline Rural & 15 & $25 \%$ \\
\hline \multicolumn{3}{|c|}{ Type of Family } \\
\hline Joint family & 23 & $38.34 \%$ \\
\hline Extended family & 2 & $3.33 \%$ \\
\hline Nuclear family & 32 & $53.33 \%$ \\
\hline Single parent family & 3 & $5 \%$ \\
\hline \multicolumn{3}{|c|}{ Educational Qualification } \\
\hline $8^{\text {th }}$ standard & 2 & $3.33 \%$ \\
\hline $9^{\text {th }}$ standard & 44 & $73.33 \%$ \\
\hline $10^{\text {th }}$ standard & 1 & $1.67 \%$ \\
\hline $11^{\text {th }}$ standard & 13 & $21.67 \%$ \\
\hline \multicolumn{3}{|c|}{ Parents Education } \\
\hline Illiterate & 2 & $3.34 \%$ \\
\hline Primary School & 1 & $1.66 \%$ \\
\hline Secondary & 8 & $13.34 \%$ \\
\hline Graduate & 33 & $55 \%$ \\
\hline Post graduate & 18 & $26.66 \%$ \\
\hline \multicolumn{3}{|c|}{ Children Staying in } \\
\hline With parents & 54 & $90 \%$ \\
\hline Hostel & 00 & $00 \%$ \\
\hline Paying Guest & 1 & $1.67 \%$ \\
\hline Rent & 4 & $6.66 \%$ \\
\hline With relatives & 1 & $1.67 \%$ \\
\hline \multicolumn{3}{|c|}{ Hours Spend with Friends } \\
\hline 8 hours & 48 & $80 \%$ \\
\hline 9 hours & 8 & $13.34 \%$ \\
\hline 10 hours & 2 & $3.33 \%$ \\
\hline 12 hours & 2 & $3.33 \%$ \\
\hline \multicolumn{3}{|c|}{ Place of Spending Time with Friends } \\
\hline School & 46 & $76.68 \%$ \\
\hline Tuition & 10 & $16.66 \%$ \\
\hline Extra activity & 4 & $6.66 \%$ \\
\hline \multicolumn{3}{|c|}{$\begin{array}{l}\text { Table 1. Percentage Wise Distribution of Samples } \\
\text { with Regards to Selected Demographic Variables }\end{array}$} \\
\hline $\mathrm{n}=60$ & & \\
\hline
\end{tabular}

The table shows percentage wise distribution of sample with regard to age, residential area, type of family, education, parent education, children stay in, hours spend with friends, place of spending time friends.

Distribution of male adolescents according to their age in years shows that, 27 (45\%) of them were belonging to the age of $13-14$ years, $22(36.67 \%)$ in the age group of $15-16$ years and remaining $11(18.33 \%)$ in the age group $17-18$ years. 
Distribution of male adolescents according to residential area shows that, 45 (75\%) of them were from urban, 25 (25\%) were from rural area. Distribution of male adolescents according to type of family shows that, 23 (38.34\%) of them were living joint family and 2 (3.33\%) were living with extended family, 32 (53.33\%) were living with nuclear family and $3(5 \%)$ were living with single parent family.
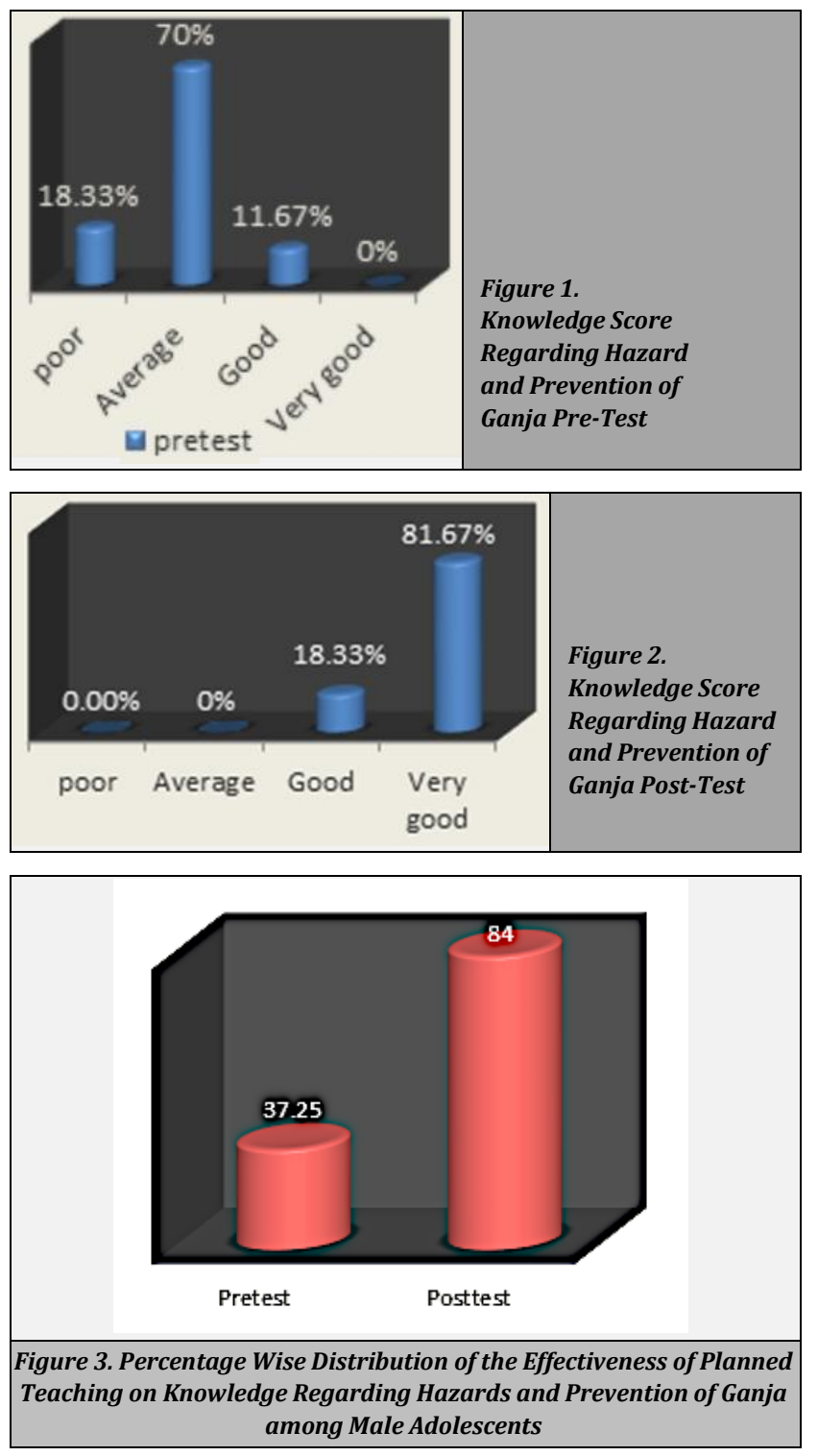

Distribution of male adolescents according to education shows that, 2 (3.33\%) of them from $8^{\text {th }}$ standard, $44(73.33 \%)$ from $9^{\text {th }}$ standard, $1(1.67 \%)$ from $10^{\text {th }}$ standard and 13 $(21.67 \%)$ from $11^{\text {th }}$ standard. Distribution of male adolescents according to parent's education shows that, 2 (3.34\%) them were illiterate, $1(1.66 \%)$ them were primary school, 8 $(13.34 \%)$ them were from secondary, 33 (55\%) them were graduate and $18(26.66 \%)$ them were from postgraduate. Distribution of male adolescents according to children staying in shows that, $54(90 \%)$ are living with parents, $1(1.67 \%)$ were living as paying guest, $4(6.66 \%)$ were living as rent and $1(1.67 \%)$ living with relatives.

Distribution of male adolescents according to hours spending with friends in shows that, $48(80 \%)$ were spending time 8 hours, $8(13.34 \%)$ were spending time 9 hours, 2
(3.33\%) were spending time 10 hours and 2 (3.33\%) were spending time 12 hours. Distribution of male adolescents according to place of spending time with friends shows that, $46(76.68 \%)$ were spending in school, 10 (16.66\%) were spending in tuition and $4(6.66 \%)$ were spending in extra activity.

The results of the study, figure No. 1 , indicate that the knowledge level of, $11(18.3 \%)$ is less of whom $42(70 \%)$ is in the average and $7(11.67 \%)$ has a good knowledge level, of which $0(0 \%)$ has a good knowledge performance. The minimum result was 0 and the score limit was 12 and the average score was $7.45 \pm 2.60$, and the mean percentage score 37 and interquartile range is 3.75 .

The pre-test indicates that neither of them has poor knowledge, the average awareness level was $0(0.0 \%)$, the good response level was 11 (18.33\%), the very good level of awareness was $49(81.67 \%)$ and There was an overall minimum score of 12 , and the overall maximum score was 20 , with an average score of $16.80 \pm 1.715$ for 84 . And the posttest indicates a substantial difference in understanding between pre-test and post-test awareness ratings. The percentage of wise distribution among male adolescents is the successful delivery of planed awareness teaching on hazards and ganja prevention. The mean pre-test value is 37.25 and Post-test value is 84, the averages of the pre-test are 2.600 , and Post-test values are 1.715. The t-value determined is 22.024 and 0.095 is p-value. Therefore, it is statistically interpreted that it was beneficial for male teenagers to learn about risks and avoid ganja.

\section{DISCUSSION}

There was no major GPA gap between the drug consumers and the non-consumers, according to Pearlman (1968), Blum (1969), Goode (1971) and Hochman and Brill (1973). These findings are noteworthy because the 2005 report of SAMHSA showed that $17.9 \%$ of students with GPA 1.0 or lower used marijuana in their last half last month compared to $3.1 \%$ with GPA 3.5 and lower in their last six months. As they found that academic participation in unusual marijuana users has increased statistically significantly, the findings of theirs independent study T-test are also in contrast to the SAMHSA assertion of 2005. 5 These are interesting results and lead to a large number of questions. Was it merely a phenomenon that statistically important? Is there also any influence which is rare for those who use marijuana? Is there a relaxing effect on the student while we use marijuana? On the contrary, these students may be using marijuana for successful academics as a "reward?"

At the other hand, their independent study t-test findings add up the evidence collected by Arrias (2013), Caldeira, Bugbee, Vincent and O'Grady say that 15 days a month in which students use marijuana twice as often as moderate users would stop in school, given there was a decreased in social engagement with users withdrawing from school. their study has shown that uncommon users of marijuana are more academically active than non-users when their findings are tested using Austin's (1985-1998) student participation theory, and according to the theory of Austin, college experience was more effective. 6 
Although the uncommon use of marijuana may help students relax and reduce the stress of university education Regarding social participation and usage based on the review literature given in this dissertation, Bell and Johnston (1997) need to research more carefully why few people are engaging with academia more closely. The findings of their research showed a lower risk of social participation for people who used marijuana more than once a day. When these findings had been discussed through the lenses of Austin's (1985) theory of student engagement, it was cleared that a heavy use of marijuana decreases the likelihood that you are socially engaged on campus. ${ }^{7}$ The findings agree with and correlate with the cultural identity theory of substance addiction by Anderson (1998), in particular with that of her theory of social marginalization and exclusion from society in general to stop and fill with a sense of dignity the otherwise marginalized student (Henderson \& Boyd, 1992). Because of the fairly poor associations between university and marijuana use and social participation, their research refers to the current literature, in which conflicting findings and nebular findings were popular. ${ }^{8}$ Although not significant, the deleterious effect of marijuana on university participation occurred more than once every week, daily and daily. In addition, a student can undergo a change in drug-related identity because heavy marihuana users suffered from fewer social involvement, as Anderson shows in her theory of cultural identity for drug abuse in 1998. This change of identity may be encouraged by social isolation because the undergraduate experience lacks social engagement. Further studies must be carried out using the model developed in this study with bigger samples from different fields. ${ }^{9}$

\section{CONCLUSIONS}

Planned teaching was highly effective in enhancing the knowledge regarding hazards of ganja, and its prevention among male adolescents in the selected senior secondary school.
Financial or Other Competing Interests: None.

\section{REFERENCES}

[1] Ling LJ, Hung SL, Tseng SC, et al. Association between betel quid chewing, periodontal status and periodontal pathogens. Oral Microbiol Immunol 2001;16(6):364-9.

[2] Chang MC, Kuo MY, Hahn LJ, et al. Areca nut extract inhibits the growth, attachment, and matrix protein synthesis of cultured human gingival fibroblasts. J Periodontol 1998;69(10):1092-7.

[3] Gupta S, Reddy MV, Harinath BC. Role of oxidative stress and antioxidants in aetiopathogenesis and management of oral submucous fibrosis. Indian J Clin Biochem 2004;19(1):138-41.

[4] Kumar S, Parmar G, Saiyed HN. Nut and tobacco chewing. Br Dent J 2004;197(6):292.

[5] Vijayalakshmi IB. Economic impact of smoking and cardio vascular disease. Tobacco and Poverty-A Vicious Circle. May 18, 2004.

[6] The ICD-10 classification of mental and behavioural disorders. Geneva: WHO Publicaion 2002.

[7] Francis JL, Mullen K. Religiosity an attitudes towards drug use among 13-15 year olds in England. Addiction 2006;88(5):665-72.

[8] Srivastava A, Pal HR, Dwivedi SN, et al. National household survey of drug abuse in India. Report submitted to the Indian Ministry of Social Justice \& Empowerment and the United Nation Office for Drug \& Crime 2003.

[9] Agurell S, Halldin M, Lindgren JE, et al. Pharmacokinetics and metabolism of delta1- tetrahydrocannabinol and other cannabinoids with emphasis on man. Pharmacol Rev 1986;38(1):21-43.

[10] Loe H, Silness J. Periodontal disease in pregnancy. I. Prevalence and severity. Acta Odontol Scand 1963;21(6):533-51. 